REVISTA DE ESTUDOS EM ARTES CÊNICAS

E-ISSN 2358.6958

\title{
Um relato de amor com Viewpoints: Ensaiando nosso "ensaiar-se"
}

Luah Guimarãez

\section{Para citar este artigo:}

GUIMARÃEZ, Luah. Um relato de amor com Viewpoints: ensaiando nosso "ensaiar-se". Urdimento - Revista de Estudos em Artes Cênicas, Florianópolis, v. 3, n. 42, dez. 2021.

doi DOl: http:/dx.doi.org/10.5965/1414573103422021e0302

Este artigo passou pelo Plagiarism Detection Software| iThenticate 


\section{Um relato de amor com Viewpoints: Ensaiando nosso "ensaiar-se"1}

\section{Resumo}

Luah Guimarãez ${ }^{2}$

Este artigo partilha livremente experiências da pesquisadora que pratica e conduz treinamento com Viewpoints no Estúdio Oito Nova Dança em São Paulo. Seu primeiro contato com Viewpoints foi em 1997 no Fall Studio Session realizado pela SITI Company em Nova York. Observa, na sua abordagem, os princípios, fundamentos e pressupostos desta técnica de improvisação e se aventura a compreender sua importância como experiência para a pedagogia e para a reflexão sobre a formação do artista das Artes da Cena.

Palavras-chave: Viewpoints. Improvisação. Pedagogia da Experiência. SITI Company. Mary Overlie.

\section{A love story with Viewpoints: Rehearsing our "self-rehearsing"}

\section{Abstract}

This article freely shares experiences of the researcher, who practices and conducts Viewpoints's training at Studio Oito Nova Dança in São Paulo. Her first contact with Viewpoints was in 1997 at Fall Studio Session, held by SITI Company in New York. She points out, in her approach, the principles, foundations and assumptions of this technique of improvisation, and ventures to understand its importance as an experience for the pedagogy and reflection on the training of the performing artist.

Keywords: Viewpoints. Improvisation. Experience Pedagogy. SITI Company. Mary Overlie.

\section{Un reporte de amor con Viewpoints: Ensayando nuestro "ensayar-se"}

\section{Resumen}

Este artículo comparte libremente experiencias de la investigadora, que practica y realiza entrenamiento con Viewpoints en Studio Oito Nova Dança en São Paulo. Su primer contacto con Viewpoints fue en 1997 en la Fall Studio Session organizada por SITI Company en Nueva York. Observa, en su planteamiento, los principios, fundamentos y supuestos de esta técnica de improvisación y se aventura a comprender su importancia como experiencia para la pedagogía y reflexión sobre la formación del artista de artes escénicas.

Palabras clave: Viewpoints. Improvisación. Pedagogías de la Experiencia. SITI Company. Mary Overlie.

${ }^{1}$ Revisão ortográfica e gramatical do artigo realizada por Ana Maria Fiorini formada em Editoração pela ECAUSP. Atua como tradutora, preparadora e revisora de textos. É editora na Unifesp.

2 Mestrado em Artes Cênicas pela Escola de Comunicações e Artes da Universidade de São Paulo (ECA-USP 2020). Graduação em Artes Cênicas pela Universidade Estadual de Campinas (UNICAMP - 1991). luahguimaraez@gmail.com

http://lattes.cnpq.br/4108659127171620 (iD https://orcid.org/0000-0003-3909-5169 
Dedico este relato a todas as pessoas com as quais partilhei o treinamento de Viewpoints.

E não me esquecer, ao começar o trabalho, de me preparar para errar. Não esquecer que o erro muitas vezes se havia tornado o meu caminho. Todas as vezes em que não dava certo o que eu pensava ou sentia - é que se fazia enfim uma brecha, e, se antes eu tivesse tido coragem, já teria entrado por ela. Mas eu sempre tivera medo de delírio e erro.

Meu erro, no entanto, devia ser o caminho de uma verdade: pois só quando erro é que saio do que conheço e do que entendo. Se a "verdade" fosse aquilo que posso entender - terminaria sendo apenas uma verdade pequena, do meu tamanho.

A verdade tem que estar exatamente no que não poderei jamais compreender.

(Lispector, 1977, p.129)

Quando criança, em Jardinópolis, interior de São Paulo, brincava de escondeesconde com os amigos dos meus irmãos mais velhos. Eu era considerada a "café com leite". Brincávamos em casa ou na rua, mas, durante uma temporada, brincamos à noite na casa do nosso vizinho, que passava por uma grande reforma, e onde com certeza era muito mais perigoso e desafiador. Assim que passávamos pelo tapume que fechava a frente da casa vinha o frio na barriga. Naquele momento da reforma, nada de luz elétrica. O "dois ou um" decidia quem seria o pegador. Quando iniciava a contagem, eu não sabia aonde estava indo me esconder, se no banheiro, na cozinha, num quarto, na sala, porque me perdia na topografia da casa em reforma. O pique eu sabia. Era na varanda, o que era um alívio, porque, pelo menos, ainda sem telhado, teria o céu, as estrelas e talvez a lua para iluminar um pouco. Eu me aventurava a me esconder em lugares muito escuros; como era pequena, escolhia os cantinhos para me encolher ainda mais. Depois que escolhia, não tinha como voltar atrás, mas batia o medo, porque eu começava a reconhecer no escuro o lugar, os cheiros de cimento fresco, de tijolo, de terra molhada, os microbarulhos, e ai de mim se eu pensasse na possibilidade de aparecer um bicho. Nesse grau elevado de excitação, lembro que todos os sentidos se aguçavam, e eu baixava a respiração ao mínimo para escutar se alguém estava prestes a me descobrir, ou, até que eu criasse coragem e irrompesse, voar até o ponto acordado como pique, onde me salvaria, ou não. A cada novo esconderijo, de alguma maneira mapeava a topografia da casa em reforma - para 
reencontrar o pique depois, não poderia me perder. Estabelecia estratégias a cada nova rodada. Havia um sentimento misturado, entre o medo e o "quero de novo". Perdia totalmente a noção do tempo a cada vez. Mas, quando o pegador estava perto de contar trinta, eu sabia que já deveria ter encontrado o lugar, e, se não tivesse encontrado o lugar, me metia rapidamente num canto, porque logo depois eu precisaria de um tempo para conter todas as sensações, e sabia que a contagem chegaria, no máximo, até cinquenta. Fora que o safado pegador, quando chegava nos quarenta, acelerava a contagem até chegar logo nos cinquenta. A urgência desses segundos - entre investigar o lugar perfeito, escolher, decidir, esconder-me, sentir medo, afiar a escuta, a atenção, a observação do espaço, a tentativa de controle da respiração, me preparar para estar pronta caso alguém me encontrasse, decidir correr até o pique em meio ao silêncio noturno - foi a sensação que voltei a experimentar na minha primeira vez com os Viewpoints, em Nova York, em 1997.

Apesar de eu ter me reconectado com essa memória de criança, os Viewpoints não são jogos dramáticos. Viewpoints é uma técnica de improvisação que faz o ser que a pratica articular categorias de tempo e espaço e treinar estar em cena em tempo integral. Prefiro, como atriz, considerá-la como um sistema, porque envolve elementos (princípios e categorias de espaço e de tempo ${ }^{3}$ que serão articulados em conjunto. Há um modo de existir nessa técnica: tecer, com autonomia, fios invisíveis entre as categorias de espaço e tempo que se tornam visíveis para a audiência. Arrisco: se tornam visíveis se os seres e corpos em cena estabelecerem relações entre o espaço, entre tempos, entre si e entre a audiência. É um treinamento relacional por excelência.

Improvisar vem do latim impromptus: im significa "em" e promptu vem de promere - pro, por sua vez, é a frente; mere, fazer surgir, conseguir. Podemos compreender que, em estado de atenção, criamos um ambiente para estarmos prontos para agir. Acrescento que no treinamento com os Viewpoints somos provocados ao longo da prática: a não agir; a segurar na pausa, que é uma condição dinâmica; a vetorizar o corpo no espaço; a contrapor; a justapor nossa resposta ao 
para estudantes iniciarem sua prática sobre o que é estar em cena, em oposição à ideia preconcebida de representação. É somente no terceiro e quarto semestres que se iniciam as disciplinas de interpretação. Durante a graduação, descobri a importância da fisicalidade nos treinamentos nomeados de "condensados", ministrados por Luís Otávio Burnier ${ }^{4}$, em 1988, naquela universidade, num momento em que os alunos decidiram não aceitar a reposição "nas coxas" proposta pelo reitor da época, após uma extensa greve, mas criaram diferentes ações pedagógicas usando os espaços físicos da universidade. Nesses "condensados", trabalhávamos a exaustão física durante cinco horas, cinco dias por semana, e, nesse treinamento, absorvi que o teatro poderia ser muito mais interessante do que eu havia experimentado até aquele momento, entre o segundo e o terceiro anos de graduação. Compreendi a partir da experiência com o corpo, na carne, exaurindo e investindo em quebrar padrões, e buscando caminhos internos.

Dez anos mais tarde, em 1997, eu estava fazendo o Fall Studio Session em Nova York com a SITI Company5. Foi com essa companhia que treinei o Método Suzuki e os Viewpoints. Outros dez anos depois, em 2007, eu entrava numa sala da Oficina Cultural Oswald de Andrade, em São Paulo, para ministrar minha primeira oficina de Viewpoints, em parceria com Juliana Monteiro ${ }^{6}$. E, de lá para cá, ministrei treinamentos com os Viewpoints no CAC da USP (2011), em Curitiba (2008), no curso de iniciação em teatro da PUC/TUCA (2016-2017), na extensão da SP Escola de Teatro (2012-2014), na Escola Livre de Dança de Santo André (2012), no Núcleo Experimental do Sesi (2012-2013), na Casa do Teatro (2016, para os

${ }^{4}$ Luís Otávio Burnier foi ator, mímico, tradutor, pesquisador e diretor de teatro. Foi um dos fundadores do grupo e do núcleo interdisciplinar de pesquisas teatrais da UNICAMP, o LUME.

${ }^{5}$ SITI Company ou Saratoga Internacional Theatre Institute é a companhia teatral, com sede em Nova York e em Saratoga Springs, NY. Foi fundada em 1992 pela diretora estadunidense Anne Bogart e pelo diretor japonês Tadashi Suzuki.

${ }^{6}$ Recomendo a leitura da tese de doutorado da pesquisadora, atriz e diretora Juliana Reis Monteiro dos Santos (2017), Sob a perspectiva do instante: o teatro como lugar de construção de espaço-tempo singular.

${ }^{7}$ A Casa do Teatro foi fundada em 1983, em São Paulo, com um curso de teatro inovador, em que a criatividade, a expressão e a comunicação de ideias em grupo motivam o desenvolvimento pessoal e a formação cultural e humana de crianças e jovens, a partir de 4 anos de idade, por meio das artes da cena - teatro, música, dança, circo, capoeira, artes plásticas. Sob a supervisão de Lígia Cortez, artistas orientadores participam do Núcleo Permanente de Extensão da Escola Superior de Artes Célia Helena, reconhecida socialmente pela excelência na formação de artistas e pesquisadores. Ministrei treinamento de Viewpoints para os professores. Tanto a Casa do Teatro como a Escola Superior de Artes Célia Helena trazem em sua história 
professores), no Célia Helena Centro de Artes e Educação (2014-2016), e, desde 2019, mantenho o treinamento no Estúdio Oito Nova Dançå, em São Paulo. Em alguns desses treinamentos, estabeleci parcerias com Fabiano Lodi e Roberta Nazaré. E, na extensão da SP Escola de Teatro, em 2013, então coordenada por Lúcia Camargo ${ }^{9}$, convidei alguns artistas que também trabalham com Viewpoints: além de Lodi e Nazaré, vieram Miriam Rinaldi10, Cristiane Zuan Esteves, Amanda Lyra e Paula Bellaguarda, porque assim eu também poderia treinar como atriz e, ao mesmo tempo, observar e aprender a partir da condução dos parceiros e parceiras.

um legado importante e único: originaram-se da fundamentação artística e pedagógica da atriz Célia Helena, que, em 1977, criou o Teatro-escola Célia Helena, com um curso pioneiro de teatro para que os jovens, a partir de 14 anos, pudessem atuar com autonomia, compartilhar ideias, exercer a reflexão sobre si e o espírito crítico sobre a sociedade e o mundo.

${ }^{8}$ O Estúdio Oito Nova Dança, espaço cultural e sede da Cia. Oito Nova Dança, foi criado em 2008 no bairro do Sumaré, em São Paulo. Foi fundado por Lu Favoreto como um desdobramento do Estúdio Nova Dança, do qual também era sócia-fundadora, que existiu entre 1995 e 2007, no bairro do Bixiga (centro da cidade de São Paulo). O Estúdio Nova Dança foi um importante espaço de referência na dança, desempenhando um papel de incubadora de várias companhias de dança na cidade de São Paulo, sediando processos criativos, formando diversos artistas e promovendo eventos de formação de público. Seguindo essa tendência, desde sua criação, o Estúdio Oito Nova Dança é um espaço voltado para o ensino, pesquisa e criação em dança contemporânea em São Paulo, reunindo profissionais e pesquisadores das artes do corpo ligados à investigação dos princípios da educação somática no estudo do corpo em movimento e na comunicação em cena. Como espaço de pesquisa, é um local de processos de investigação criativa, tanto da Cia. Oito Nova Dança, companhia a qual sedia, como de outros grupos de pesquisa e criação em dança, teatro e música, com forte influência da linguagem da improvisação, tanto como procedimento de levantamento de matéria criativa quanto como meio de investigação e comunicação na cena. Abriga o T.E.I.A (Territórios de Encontros Intensivos Artísticos), vivência tecida coletivamente numa troca de conteúdos artísticos improvisados (2018 a 2021).

9 Lúcia Camargo é jornalista e pedagoga, mas se destacou como gestora cultural. Ocupou cargos na administração pública no Paraná e em São Paulo. Foi gestora e coordenadora dos cursos de extensão da SP Escola de Teatro até seu falecimento, em 20 de julho de 2020.

${ }^{10}$ Recomendo, como material de pesquisa, o tema do doutorado da atriz e pesquisadora Miriam Rinaldi (2016), Teoria e prática do Viewpoints. 
Figura 2 - Sessão aberta de improviso. Débora Ballarini e Marcella Vicentini no chão. De pé, Stephanie Teramae, Beatriz Morelli e Priscila Torres. Foto: Fábio Stamato

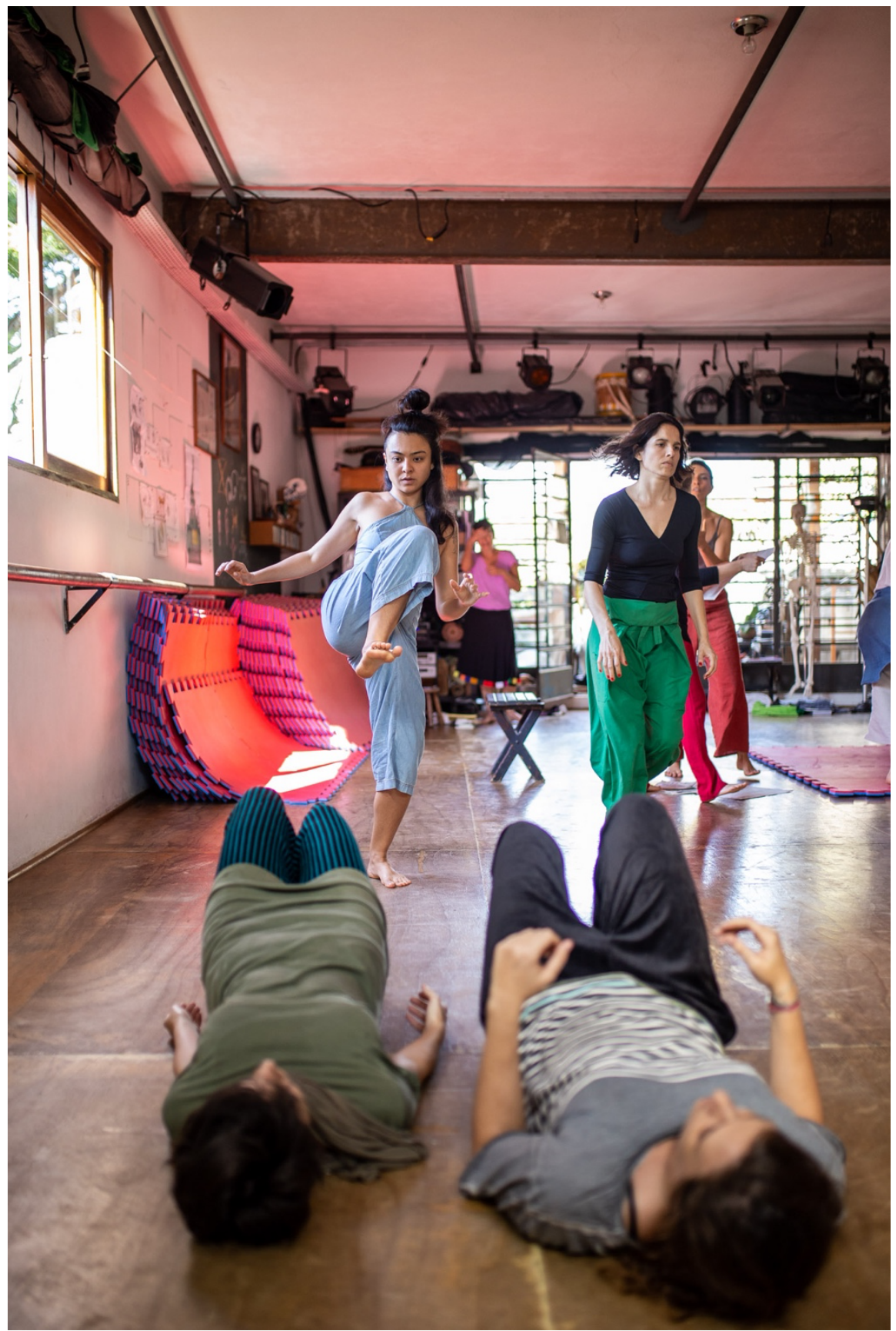

Sete anos mais tarde, em 2014, voltei a Nova York por apenas três meses, com os meus filhos, acompanhando meu ex-marido. Narrei minhas experiências com a prática do Viewpoints para Ellen Lauren11: pude dar ao vivo meu depoimento

${ }^{11}$ Ellen Lauren integra a SITI Company há 29 anos e é membro-fundadora da SITI Dance Company. Ensina o Treinamento Suzuki e é artista associada da Suzuki Company of Toga (SCOT), sob direção de Tadashi Suzuki. Recebeu o prêmio Fox Fellowship for Distinguished Achievement. Publicou, na American Theatre Magazine. 
a ela sobre a exímia condução de Fabiano Lodi com o Método Suzuki, porque, na volta ao Brasil, iríamos propor um treino de Suzuki e Viewpoints juntos na SP Escola de Teatro. Observei um dia de treinamento no conservatório da SITI com o método Suzuki, treinei com ex-alunos da companhia uma vez por semana no Brooklyn e durante uma semana no espaço da SITI, enquanto eles viajavam com um espetáculo.

Assisti a um treino conduzido por Mary Overlie ${ }^{12}$ - a criadora dos Six Viewpoints - no Experimental Theater Wings ${ }^{13}$. Mary topou me receber para que eu observasse um dia de treino. Os jovens estudantes chegaram e, sem que ela precisasse dizer uma palavra, iniciaram um aquecimento no chão, como se fosse uma espécie de barra no chão, um aquecimento a partir de alinhamentos, organização motora e vetorização no plano baixo. Em seguida, iniciaram aos poucos o que me parecia um fluxo (flow), só que não pararam mais o trabalho. Eu reconhecia que era uma sessão, um improviso, mas era uma profusão de acontecimentos, uma polifonia absoluta entre os participantes. Sincrônicos, pareciam até mesmo ensaiados, tamanha a escuta entre eles. E foi a primeira vez que escutei a condução da Mary Overlie. Ela só dizia: "Come up with an unnecessary!"14 Eu me reconheci na alegria dos seus olhos observando os acontecimentos. Ao final, nos despedimos, eu disse a ela que eu havia amado a sessão, e que ela me lembrava um diretor de teatro brasileiro - eu estava me referindo ao Zé Celso Martinez Correa. Eles tinham algo em comum no olhar, profundo, que varre a alma da gente por dentro. E ela, rindo, me perguntou se ele era um bom diretor. Eu disse: “Ele é esplêndido, fenomenal!”, e descrevi um pouco como era o Teatro Oficina.

em janeiro de 2011, o artigo "In search of stillness". Atualmente, escreve o livro The Invisible body, sobre sua experiência com a Suzuki Company. É professora do Departamento de Drama da Juilliard desde 1995 e artista convidada regular na TEAC National Academy (Helsinki), na Universidade da Califórnia em Los Angeles (UCLA, Estados Unidos) e na Windsor University (Canadá).

${ }^{12}$ Mary Overlie faleceu em 5 de junho de 2020. Foi coreógrafa, dançarina, professora e criadora da técnica dos Six Viewpoints. O Experimental Theater Wings (ETW) é um departamento da Tish School of Arts, da New York University. Em 2016 escreveu o livro Standing in Space: The Six Viewpoints Theory \& Practice.

${ }^{13}$ O Experimental Theater Wings (ETW) é um departamento da Tish School of Arts da New York University.

${ }^{14}$ O capítulo 14 do seu livro é dedicado ao unnecessary. Ela escreve: "It is important to experience that there are limitless resources in the Unnecessary", p.122. 
Figura 3 - Treinando resposta cinestésica - Vini Ferez, Maria Fernanda batalha, Morgana Siqueira, Duda, Alice Guêga, Daniel Rechtman, Gustavo Curado. Viewpoints na Praça Belisario Távora em São Paulo dia 26 de setembro de 2021. Catarina Guimarães Machado

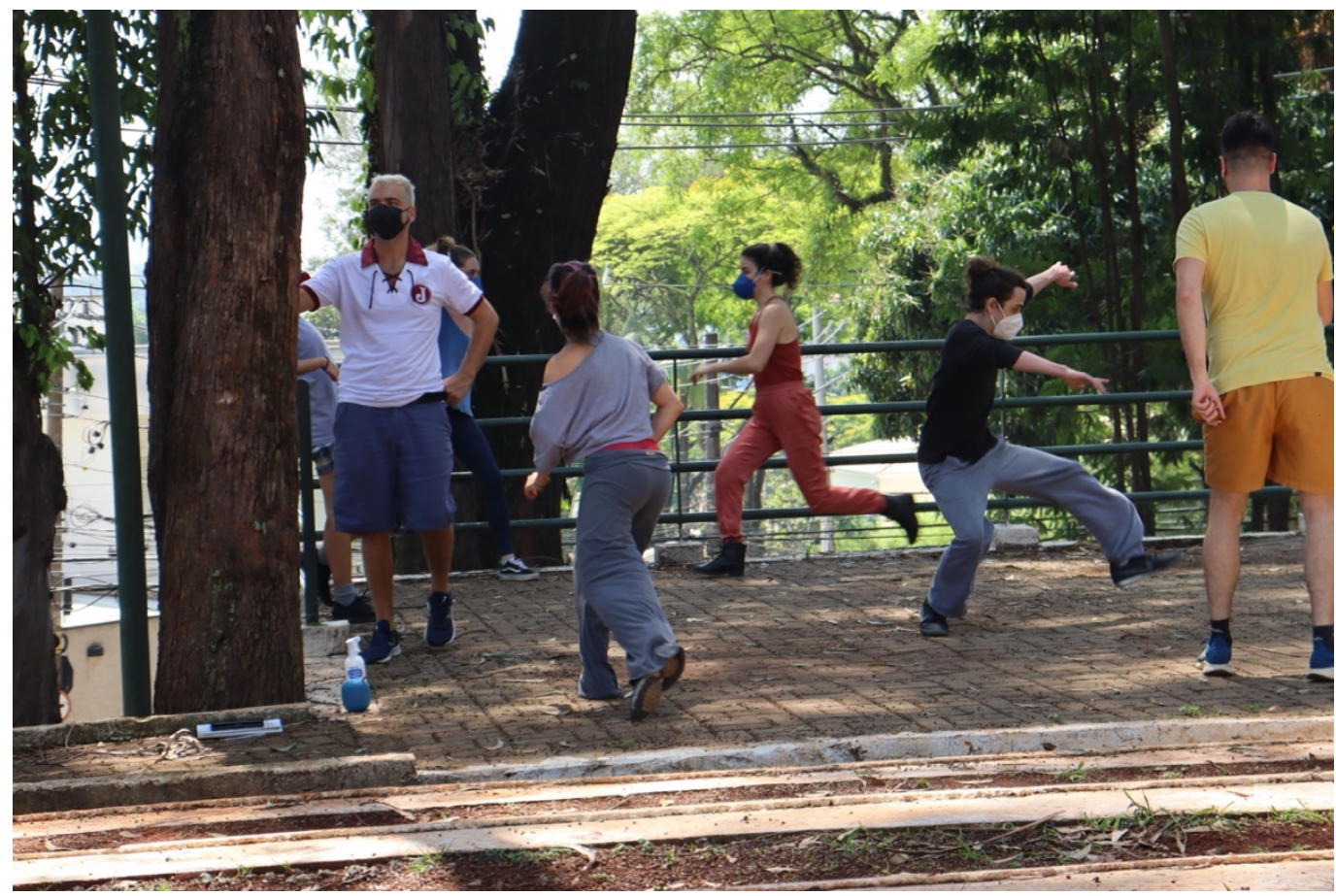

Gosto da sala de trabalho, tenho prazer em espantar a preguiça, tirar a poeira e escutar meu corpo. Um dia de trabalho numa sala é um rito para abrir os campos possíveis de probabilidades, "investigando", como escreveu Eleonora Fabião, "minutagens e métricas", porque "desautomatiza mecânicas perceptivas, cognitivas e comportamentais" (2010, p.324). Gosto de suar a camisa, a camisa da imaginação, gosto de me pegar no pulo, imaginando o que poderia acontecer diante de uma sessão de improviso, e aquilo que imaginei não acontecer. Assim, amo ser surpreendida pelas pessoas numa sala de ensaio. Mais que isso, gosto mesmo de acompanhar os caminhos e descaminhos dos seres numa sala de trabalho.

Eu me considero um pouco "velha guarda" dos Viewpoints, porque gosto de conduzir pensando numa pedagogia específica para aquele coletivo. Certamente, ao planejar um treino, o ponto de partida é o de uma atriz que viveu experiências a partir de poéticas dos processos de criação, principalmente com a mundana companhia, com a qual trabalhei de 2007 a 2019. Conduzo como se eu fosse 
treinar, pensando empaticamente o que uma atriz necessita para se entregar num dia de trabalho. Um treino, do meu ponto de vista, precisa ter uma duração de pelo menos duas horas e meia, seguindo cinco eixos: aquecimento; investigação sobre o tempo em uníssono e escuta extraordinária; fluxo (flow); investigação sobre alguma categoria de espaço e tempo; e sessões de improvisação. Esse treinamento tem vocação para formar coletivos, a partir das diferenças de cada indivíduo. Já pratiquei com parceiros que não conduzem um aquecimento coletivo, que observam o aquecimento individual dos participantes. Gostei da experiência, mas prefiro unir os participantes durante o aquecimento como se, desde o momento inicial, pudéssemos ir convocando investigações no corpo, relacionando-as com as investigações das categorias, mesmo percebendo, ao longo dos anos, que as respostas são diferentes entre os participantes e que as diferenças entre as naturezas artísticas dos parceiros e parceiras de treino enriquecem a experiência.

Figura 4 - A atriz Sofia Botelho durante aquecimento no Estúdio Oito Nova Dança, 2019. Foto: Fábio Stamato

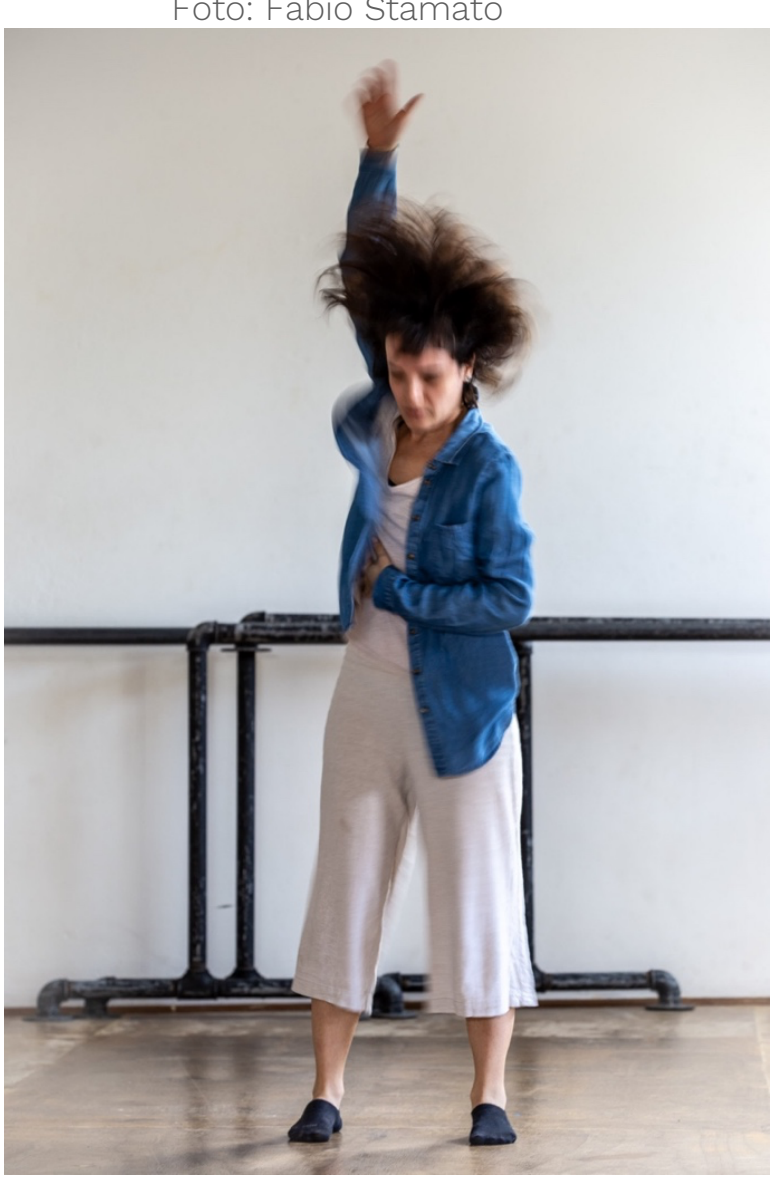


Escuto nos olhos das parceiras e parceiros o que os corpos e as almas estão pedindo como aquecimento. Muitas vezes, planejo o aquecimento, mas, ao observar cada ser, descubro que preciso alterar a proposta. Já alterei o planejado apenas por conta de um parceiro. É delicado mencionar isso, pelo risco de me tornar subjetiva e abstrata, mas é muito importante considerar que a condução de um treino contém, como fonte, a escuta sobre o coletivo e a intuição.

O aquecimento numa condição presencial de treino precisa desembocar no uníssono, ou seja, a busca daquele coletivo de estar no mesmo espaço e no mesmo tempo, no mesmo andamento. O comprometimento é a busca, a escuta, a atenção, e não o resultado. Observamos sem críticas, naquele dia de treino, quase como metáfora do coletivo, como o espaço/tempo está sendo experimentado.

Figura 5 - Aquecimento investigando o uníssono Teatro Tuca Arena, PUC São Paulo, Turma de 2017 em Iniciação Teatral - Foto Fábio Stamato

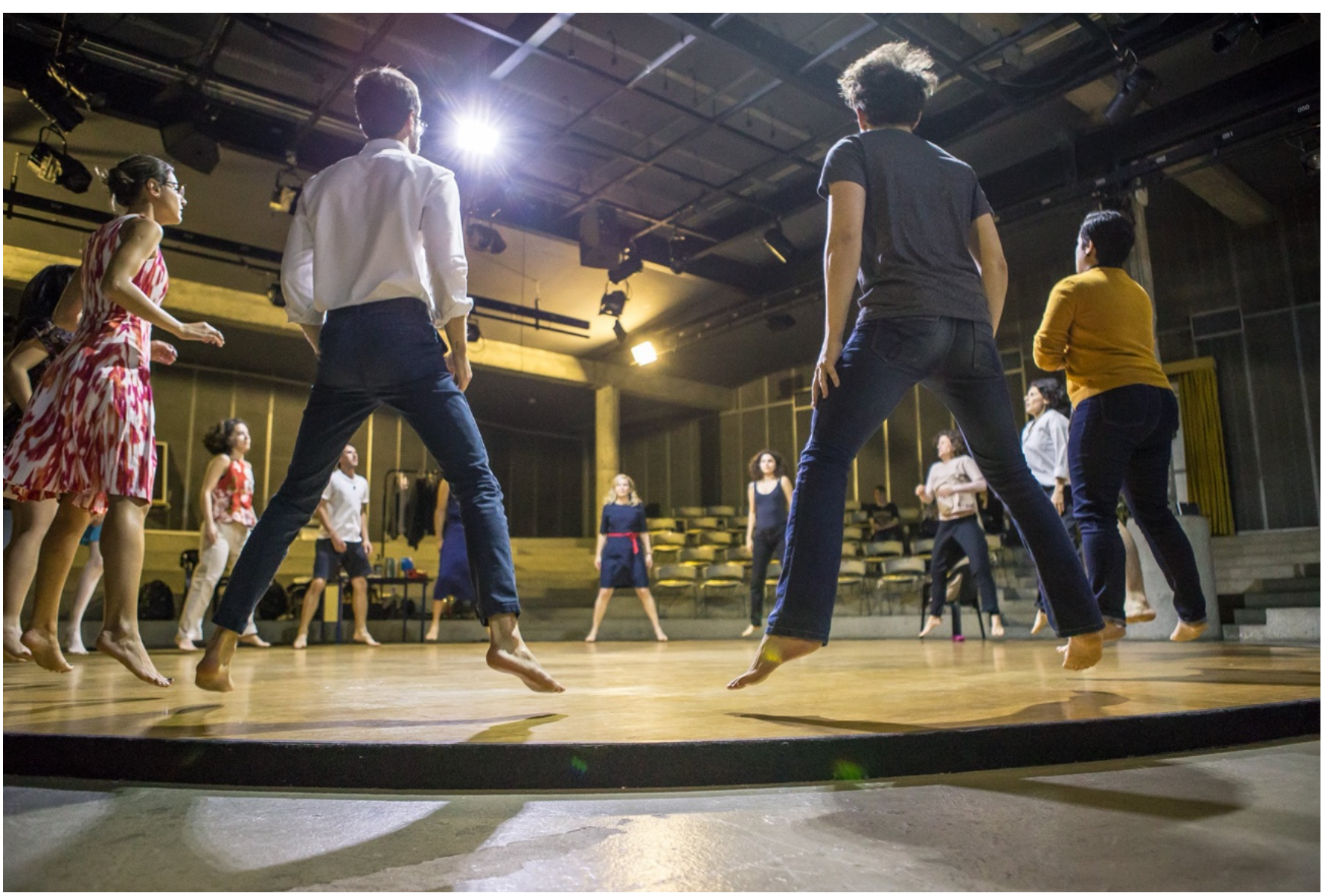


Entramos no treino com o flow/fluxo, adorado por todos. Testamos como está o fluxo entre nós, entre a sala. Investigo como o coletivo está tecendo os fios invisíveis entre eles. Checo se há pulsação, se os princípios estão presentes: escuta extraordinária, visão periférica, olhar suave, atentividade. O flow, para quem conduz, funciona como um scanner. Não existe um fluxo automático; no treinamento do fluxo, não existe método. Muitas vezes, é preciso investir e redescobrir a qualidade porosa do fluxo. Usualmente, é preciso romper com padrões preconcebidos, encorajar integridades na quebra dos padrões. Tem dias em que a gente precisa retomar princípios e convocar investigações sobre o andamento para que alguma coisa surja ou desapareça. Precisamos checar se o fluxo entre os parceiros, entre espaço e tempo, está sendo tecido autenticamente, com escuta.

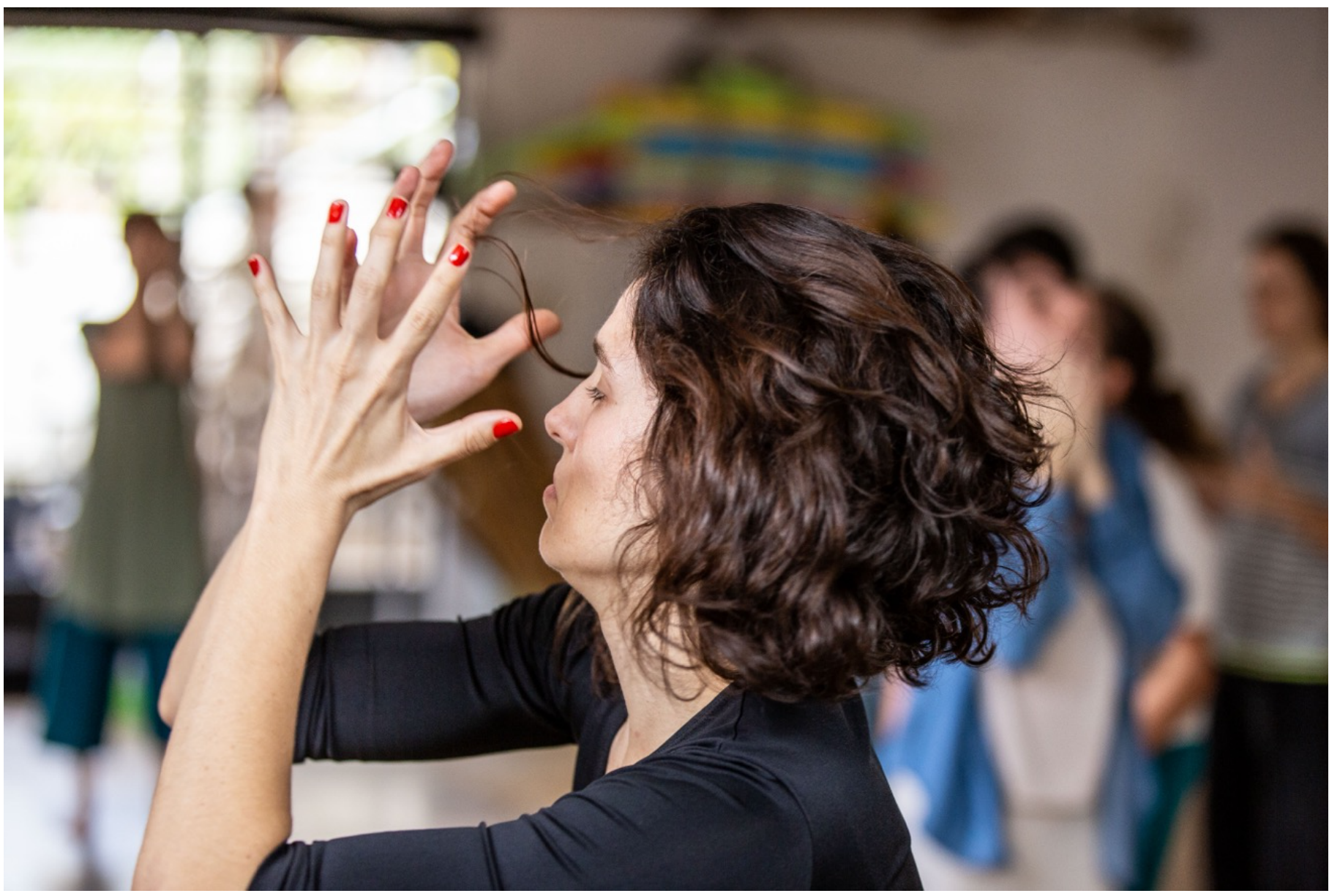


Se estamos falando de um coletivo que ainda está sendo introduzido nas categorias de tempo e espaço, inicio uma introdução logo após o treino com o fluxo. Iniciamos uma investigação individual. "Botar a mão na massa", como costumo dizer. Se é um coletivo que já foi introduzido nas categorias, os próximos passos são infinitos, e a escolha e a decisão estarão diretamente relacionadas com o treino anterior, ou com o que já emergiu como proposta naquele dia. Há pouco mencionei o fato de me considerar da "velha guarda", pois, quando introduzo uma categoria, quero fazê-los suar, criando gestos movidos a partir de determinada categoria, inspirados - nas palavras de Eden Silva Peretta (2019, p.393) - pela "dimensão corporal da linguagem-sentimento sobre o mundo". Partilho com ele a ideia de que cada sujeito, para construir sua presença, há que suar por "um gesto entendido como uma espécie de secreção resultante da implosão de uma expressividade que se sujeita às verdades da matéria" (Peretta, 2019, p.393). E, aos poucos, os corpos se estimulam a rasgar e quebrar com os padrões. Ou, ao menos, a se perguntar: "Por que é que sempre recorro a esse padrão?". 
Figura 7 - Treinando o fluxo. Viewpoints na Praça Belisario Távora em São Paulo dia 26 de setembro de 2021 - Carmen Estevez, Maria Fernanda batalha, Maria Eduarda Machado, Morgana Siqueira, Marcella Vicentini, Laís Junqueira, Alice Guêga, Daniel Rechtman e Priscila Torres. Foto: Catarina Guimarães Machado

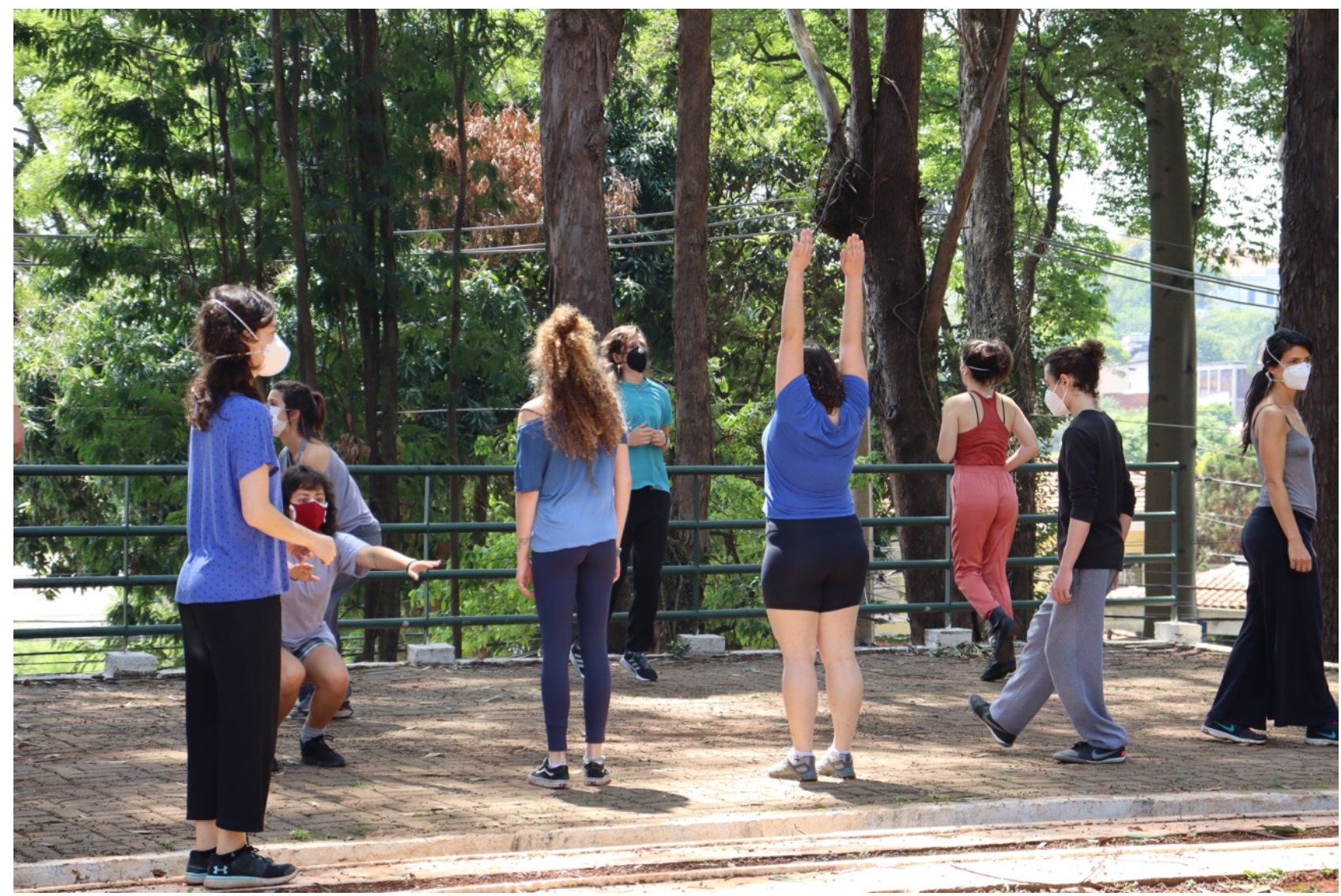

E logo depois vem o abismo, o "nonada". É como gosto de nomear o momento anterior ao início de uma sessão aberta de improviso dos/com os Viewpoints. Esse abismo, que também significa entrar numa espécie de vazio, poderia ainda ser compreendido como uma suspensão no tempo. Os anos têm me feito compreender que, se os parceiros entram neste abismo juntos, em uníssono, porém, cada um ao seu modo de existir, brota a coragem de verdadeiramente se entregar numa rede de afecções ${ }^{15}$. Esse momento relaciono diretamente com as sensações na brincadeira do esconde-esconde.

15 O uso da palavra afecções, aqui, está relacionado ao campo da filosofia e, em particular, a Espinosa. Afecção é quando a presença de um outro corpo produz efeito sobre nosso corpo. As afecç̃es são este encontro pontual de um corpo com outro. Somos corpos que se relacionam com outros corpos; quando sofremos suas afecções, quando somos afetados pelos outros corpos, sofremos uma alteração, uma passagem, um atravessamento. 
Parafraseando Guimarães Rosa (1965, p.9), significa enfrentar o "nonada”16. Uso também essa palavra, para reafirmar a sensação do abismo, porque uma sessão de improviso é uma travessia, uma experiência. Nós não temos um tema, um material ficcional, e nem sequer um texto. Estamos diante de um vazio, talvez tenhamos somente a latência do desejo. Quero me debruçar sobre esse instante de abismo, que pode se desdobrar em minutos, e dar um testemunho do ponto de vista de quem conduz. Encorajo os participantes para que o verbo de ação seja espreitar, e não esperar alguma "coisa" do(s) parceiro(s). Passei a usar o verbo espreitar depois de ler o artigo “Em busca (e à espreita) de uma pedagogia para o ator", da Tatiana Motta Lima (2017). No seu artigo, a pesquisadora reflete sobre uma das definições do verbo:

Já no espreitar, outra forma de pensar a temporalidade está em jogo: observa-se, olha-se atentamente, indaga-se. O verbo espreitar aparece na relação com o momento presente, na relação com o ambiente no qual se está. O olhar que se espreita não tem certezas prévias, ele se organiza a partir das pistas encontradas (e diversas a cada dia), trabalha com as circunstâncias e as diferenças (Lima, 2017, p.38).

Observo os olhos dos participantes e como as naturezas artísticas são distintas entre eles. Sorvo cada microdetalhe de cada um deles, atenta ao coletivo. Fico encantada com a forma como cada ser aciona internamente o trabalho psicofísico e confesso que cada um deles o faz de maneira muito singular. Por exemplo, ao observar os olhos nesse momento de abismo, posso notar que uns posicionam os olhos na parte de trás do cérebro; alguns acionam a visão periférica mais à frente, criando um campo de atenção; existem os seres que são porosos, consideram de partida a sala como audiência, e o tempo presente já está instaurado; há aqueles que me dizem "sou corpo, logo existo"; e, também, os que ainda não encontraram o seu modo de existir, que estão em vias de descobrir, mas que ainda titubeiam, que dançam os olhos, que arrumam o cabelo ou a camisa umas cinco vezes, talvez porque ainda estejam com medo de enfrentar o abismo. Meu coração aquece e dispara quando o silêncio se instaura na sala,

${ }^{16}$ Guimarães Rosa inicia a narrativa do romance Grande Sertão: Veredas com a palavra nonada. Refletindo sobre o romance, penso que, a partir dessa sugestão, "nonada", há uma travessia, um caminho, uma experiência. O escritor termina seu livro com a palavra "travessia” e o símbolo do infinito. 
unindo os abismos. Chego a sorrir. Posso escutar um alfinete caindo na Finlândia nesse segundo, tamanha é a integridade desse "império do presente", como escreveu Clarice Lispector (1977) em A paixão segundo G.H. E, quase sem respiração, espreitamos o que vai acontecer. Então, também treinamos sobretudo o "entrelaçamento" do Merleau-Ponty, porque se configura como condição dessa prática. Eleonora Fabião cita o filósofo no seu artigo: "em vez de rivalizarmos com a espessura do mundo, a espessura do meu corpo é, ao contrário, o único meio que possuo para chegar no âmago das coisas, fazendo-me mundo e fazendo-as carne" (Merleau-Ponty apud Fabião, 2010, p.323)17. Porque, nesse treinamento, um dos pressupostos é checar a observação, o espaço de recepção da audiência. E, assim, poderemos cotejar as experiências, os acontecimentos, as relações estabelecidas, e checar: por que, como, onde, quando e por quanto tempo nos interessaram ou nos desinteressaram "as coisas" que aconteceram.

Figura 8 - Estúdio Oito Nova Dança, 2019. Da esquerda para a direita: Luah Guimarãez (de costas), Giuliana Rocha, Sofia Botelho, Beatriz Morelli, Débora Ballarini, Stephanie Teramae, Juliana Schneider, Alice Guêga, Marcella Vicentini e Priscila Torres. Foto: Fábio Stamato

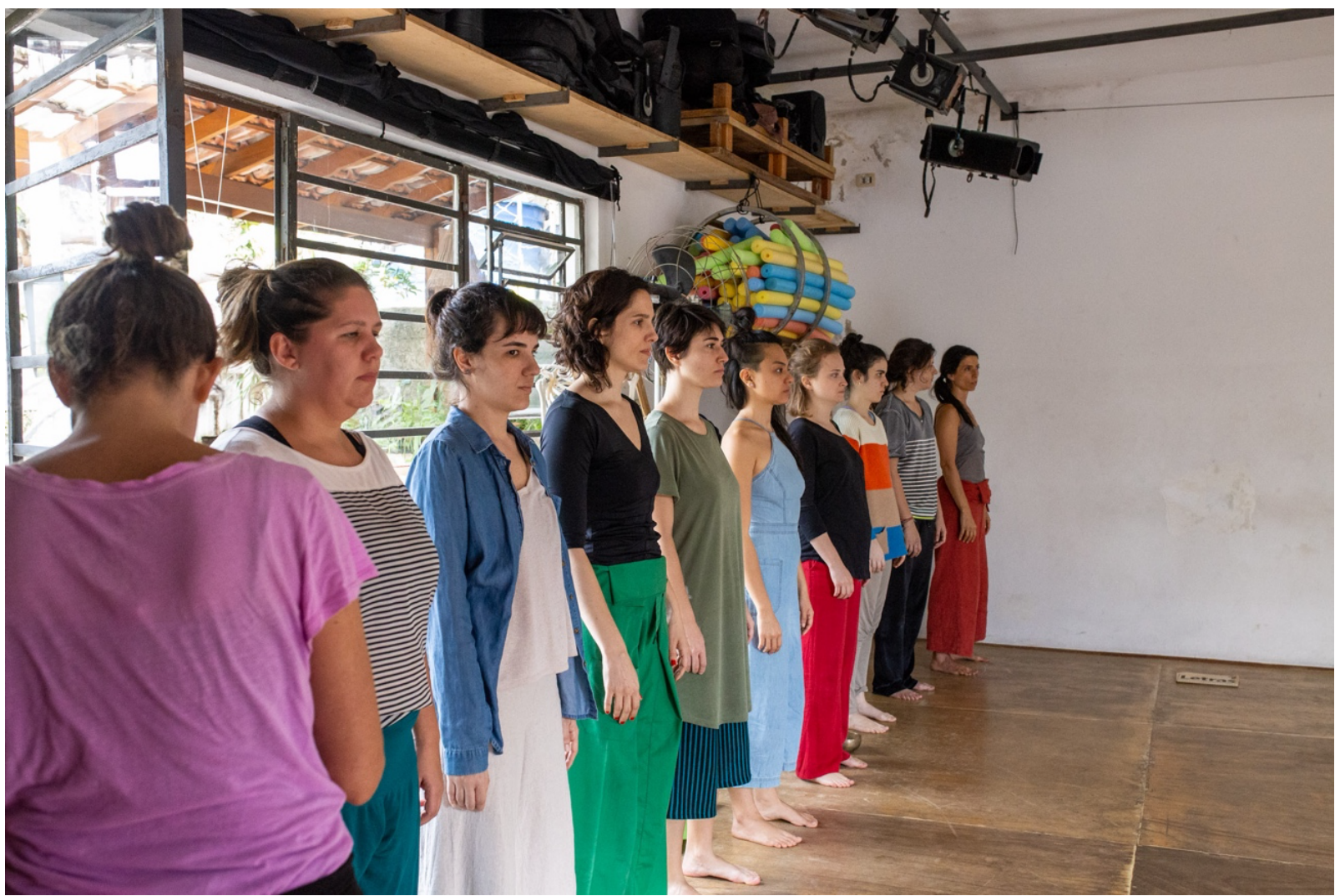

${ }^{17}$ Maurice Merleau-Ponty, The visible and the invisible. Evanston: Northwestern University Press, 1992, p.135. 
Se considero o corpo como "o único meio que possuo para chegar no âmago das coisas, fazendo-me mundo e fazendo-as carne", não posso deixar de refletir sobre a noção de encarnação do sistema de Stanislávski. Coincidentemente, enquanto me debruço neste relato sobre o treinamento, escrevo também uma resenha do extraordinário livro Stanislávski e o trabalho do ator sobre si mesmo, de Michele Almeida Zaltron (2021), para a revista Questão de Crítica. A pesquisadora se debruçou minuciosamente sobre a obra e, principalmente, sobre duas noções do sistema de Stanislávski: a perejivánie ${ }^{18}$ (a experiência do vivo ou vivência) e a voploschênie (encarnação). O livro publicado nasceu a partir de sua pesquisa de doutorado. Serei breve, porque quero apenas observar que, nesses anos conduzindo treinamentos, enxerguei na prática que, durante o treino, emergem experiências dos participantes (atrizes, atores, artistas do movimento, da dança, filósofos, músicos, fotógrafos) que se cruzam com as duas noções. Talvez eu as enxergue porque a minha raiz nas artes da cena parte de ser-atriz. Eu não estou, com essa observação, afirmando que treinamos as noções stanislavskianas, longe disso, mas sim que elas emergem durante a experiência, ao encarnarmos o tempo/espaço no corpo-carne. Notei nos parceiros e parceiras que cada um deles transita por entre essas noções, mesmo sem saber nomeálas, porque uma sessão aberta de improviso nos propõe a experiência de uma "certa vida" em movimento pela ação, emoldurada por uma "certa duração" no tempo. Não há um fim. Como resultado, existe a busca; só existe o fim porque a condição cênica é finita, e, assim, compreendo a dimensão do caráter processual do trabalho do ator pelo seu envolvimento psicofísico numa sessão de improviso.

Ao longo desses anos, fui fulminada por inesquecíveis experiências, e muitas vezes "dormi com" elas, como costumo dizer aos parceiros. Conduzo treinamentos, orientações e provocações artístico-pedagógicas porque acredito que, a partir delas, podemos constituir um campo da pedagogia da experiência nas artes da cena.

Vou citar duas experiências inesquecíveis, que, por coincidência - traindo

18 "[...] a perejivánie é ao mesmo tempo processo e resultado; ou melhor, é resultado em processo. Trata-se do resultado de um processo criativo que, por isso mesmo, não se fixa - permanece em movimento, em desenvolvimento cumulativo, pois deve se manter vivo, orgânico. A conquista da organicidade em cena é o seu objetivo principal. Para Stanislávski, o alcance da organicidade se dá pelo envolvimento psicofísico (integralidade física, mental e emocional) do ator na execução da ação" (Zaltron, 2021, p.160-161). 
minha própria escrita quando, ainda há pouco, escrevi que "nós não temos um tema, um material ficcional, e nem sequer um texto" -, tiveram cada qual um romance como tema. Uma de minhas paixões é trabalhar teatro a partir da literatura, e não da dramaturgia. Em cada uma dessas experiências, o coletivo havia analisado profundamente um romance.

A primeira experiência se deu entre alunos de graduação em Artes Cênicas da turma zero/oito da USP e artistas estrangeiros como alunos especiais, em 2011. Treinamos Viewpoints durante uns seis meses, duas vezes por semana. E, conjuntamente, analisamos o romance Noites brancas, de Dostoiévski. Um dia, iniciamos uma sessão de improviso, e o coletivo se sintonizou de tal maneira que não havia mais sentido parar a sessão, porque eles atravessaram o romance. Não há registros, a não ser em nossas memórias. Os atores e atrizes explodiram o romance em experiência, ressignificando os seus próprios materiais. Foi uma sessão longa, que eu testemunhei, e dela guardo o impacto de um coletivo apaixonado, articulando, com liberdade e escuta ímpar, tempo e espaço. O único objeto que usaram foi uma cadeira, a sala 21 do Departamento e seus corpos. Uma profusão de acontecimentos se multiplicando pelo espaço, em diversos focos se constituindo em sincronia, resultando numa polifonia de vozes, mas com uma escuta extraordinária entre eles.

A segunda experiência se deu durante a pandemia de Covid-19, em junho de 2020. Treinando pela plataforma Zoom, três intérpretes iniciaram uma sessão sobre o romance Uma aprendizagem ou O livro dos prazeres, de Clarice Lispector. Surpreendentemente, as três abriram com o tema do feminino, cada qual a seu modo, tecendo uma espécie de desejo, de flutuação-invertida entre objetos-luz e cabelos, entre sopros-falas-respiro-sufocamento, e, de repente, uma das atrizes desliga a câmera, segundos depois volta a ligar a câmera e entra debaixo do chuveiro, num gesto expressivo ${ }^{19}$ para respirar líquidos. Esse acontecimento se inscreveu como uma espécie de epifania, uma sensação de compreensão da essência das coisas. Aquilo me fez pensar: retomar o presencial também nos trará

\footnotetext{
${ }^{19}$ Gesto expressivo é uma das categorias de espaço. Investigam-se gestos comportamentais ou cotidianos e gestos expressivos. "Um movimento envolvendo uma parte ou partes do corpo; o Gesto é a forma com um começo, meio e fim." E, ainda: "Expressa um estado interno, uma menção, um desejo, uma ideia ou um valor" (Bogart; Landau, 2017, p.28)
} 
saudades das potências que descobrimos treinando Viewpoints a distância.

Os parceiros e parceiras de treino muitas vezes perguntam:

Mas não é possível repetir uma sessão aberta? Mas como você usa os Viewpoints para criar? Por que então não usamos este espaço/tempo terrivelmente fértil que se instaura entre nós para criarmos juntos, para montarmos uma peça?

E eu respondo:

Mas nós já não estamos criando juntos? Ensaiando nosso ensaiar-se?

Jorge Larrosa (2004) teceu considerações sobre o ensaio como uma das linguagens da experiência no seu artigo "A Operação Ensaio”. Larrosa refletiu sobre a experiência da escrita do ensaio, como obra de reflexão, a partir de Foucault. No artigo, escreve sobre o que significa ensaiar e o que significa ensaiar-se, pensando do ponto de vista de um escritor. Seu artigo iluminou profundamente os momentos de escrita do meu mestrado.

Se pensarmos em pedagogia atoral, o que pode um ser envolvido com as artes da cena fazer para estar pronto para agir senão praticar? Senão ensaiar-se ou ensaiarmo-nos, improvisando a cena?

Para este relato, voltando ao artigo de Larrosa, chego à conclusão de que treinar com os Viewpoints é ensaiar: ensaiar-se ou ensaiarmo-nos, uma experiência do momento presente, ao vivo, sem combinações, e sim partindo de provocações, investigações e buscas autônomas sobre um tempo/espaço de improvisação. Uma improvisação que ainda pretende ser criação, mas que se produz como experiência e que dá o que pensar como experiência porque se dá a ver. E, por essa experiência se dar a ver, forja reflexões sobre composições possiveis nas artes da cena.

Ao longo desses anos, encontrei uma expressão que se tornou um bordão entre os meus parceiros e parceiras de treino e de sala de ensaio: durma com essa! O que significa que treinar, ou ensaiar-se, implica experimentar e, portanto, praticar a metodologia do erro. Apreendemos, durante o treino, porque 
desvelamos questões a partir da experiência, muitas vezes pela ausência, por nossa capacidade de imaginar subjetivamente o que poderia ter acontecido, e nem sempre conseguimos resolvê-las. Mas como é importante "dormirmos" sobre as reflexões que surgiram a partir da experiência! Praticar a metodologia do erro não é confortável - é o oposto disso, é estarmos dispostos à vulnerabilidade em tempo integral. É ser pega em flagrante quando você está se escondendo, quando perdeu uma oportunidade, quando não percebeu onde estava o foco da audiência, quando não insistiu em perscrutar as relações que criou, e é ter consciência de que você as abandonou. Por tudo isso citei Clarice Lispector no início: parece que a gente apreende não só pelo que se dá a ver, mas também pela ausência.

[...] pois só quando erro é que saio do que conheço e do que entendo. Se a "verdade" fosse aquilo que posso entender - terminaria sendo apenas uma verdade pequena, do meu tamanho.

A verdade tem que estar exatamente no que não poderei jamais compreender. (Lispector, 1977, p.129).

Também uso essa expressão em sala de ensaio de um processo de criação, quando os artistas envolvidos ainda não tocaram com profundidade num determinado tema, porque talvez ainda não estejam prontos para atravessar aquele tema. 
Figura 9 - Quando a Praça nos dá as Raias - Viewpoints na Praça Belisario Távora em São Paulo dia 26 de setembro de 2021 - Daniel Rechtman, Morgana Siqueira, Carmen Estevez e Gustavo Curado. Foto: Catarina Guimarães Machado

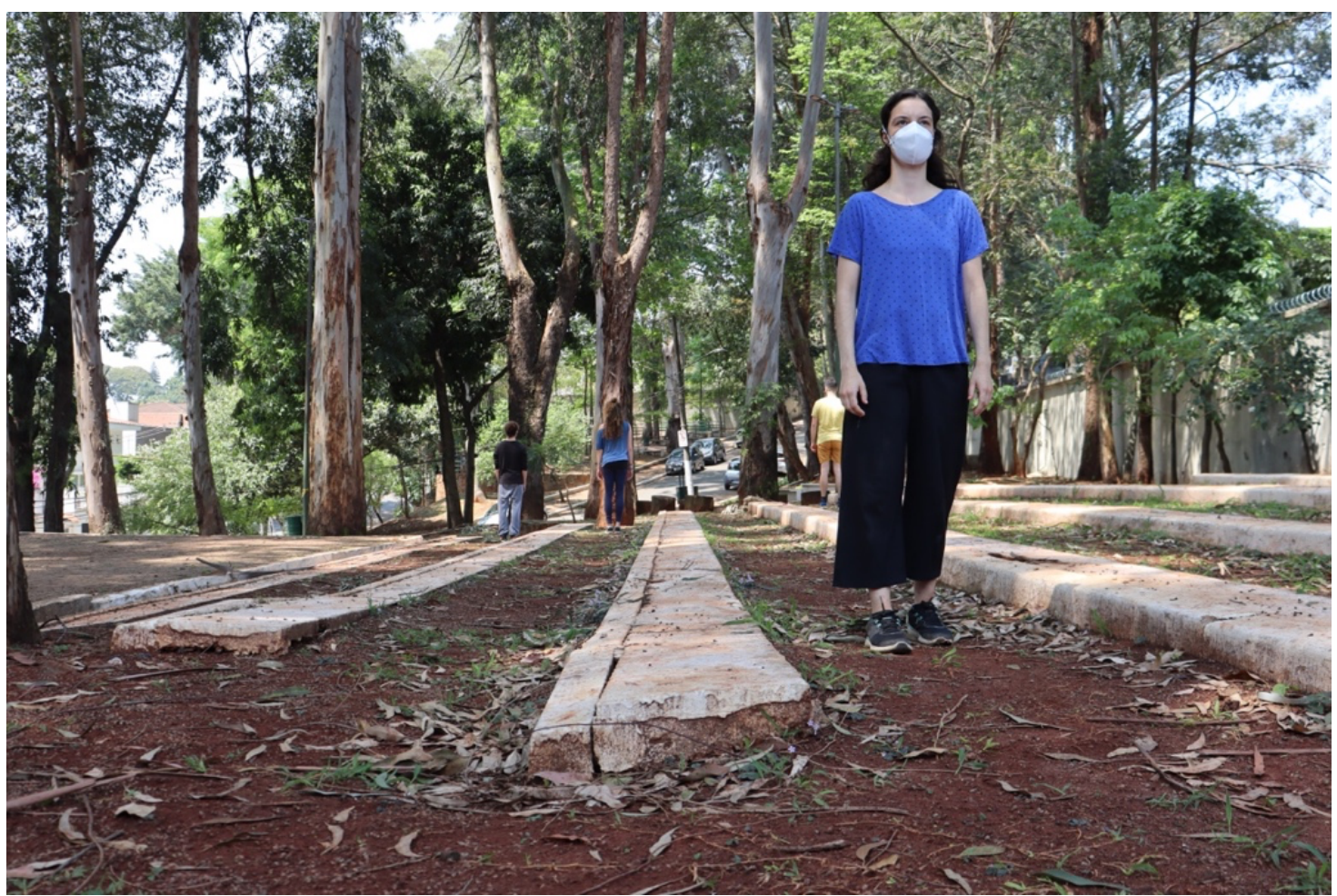

Figura 10 - Quando elas quebram as regras e invadem as raias - Viewpoints na Praça Belisario Távora em São Paulo dia 26 de setembro de 2021 - Maria Fernanda Batalha, Daniel Rechtman, Marcella Vicentini, Morgana Siqueira, Alice Guêga, Carmen Estevez e Priscila Torres. Foto: Catarina Guimarães Machado

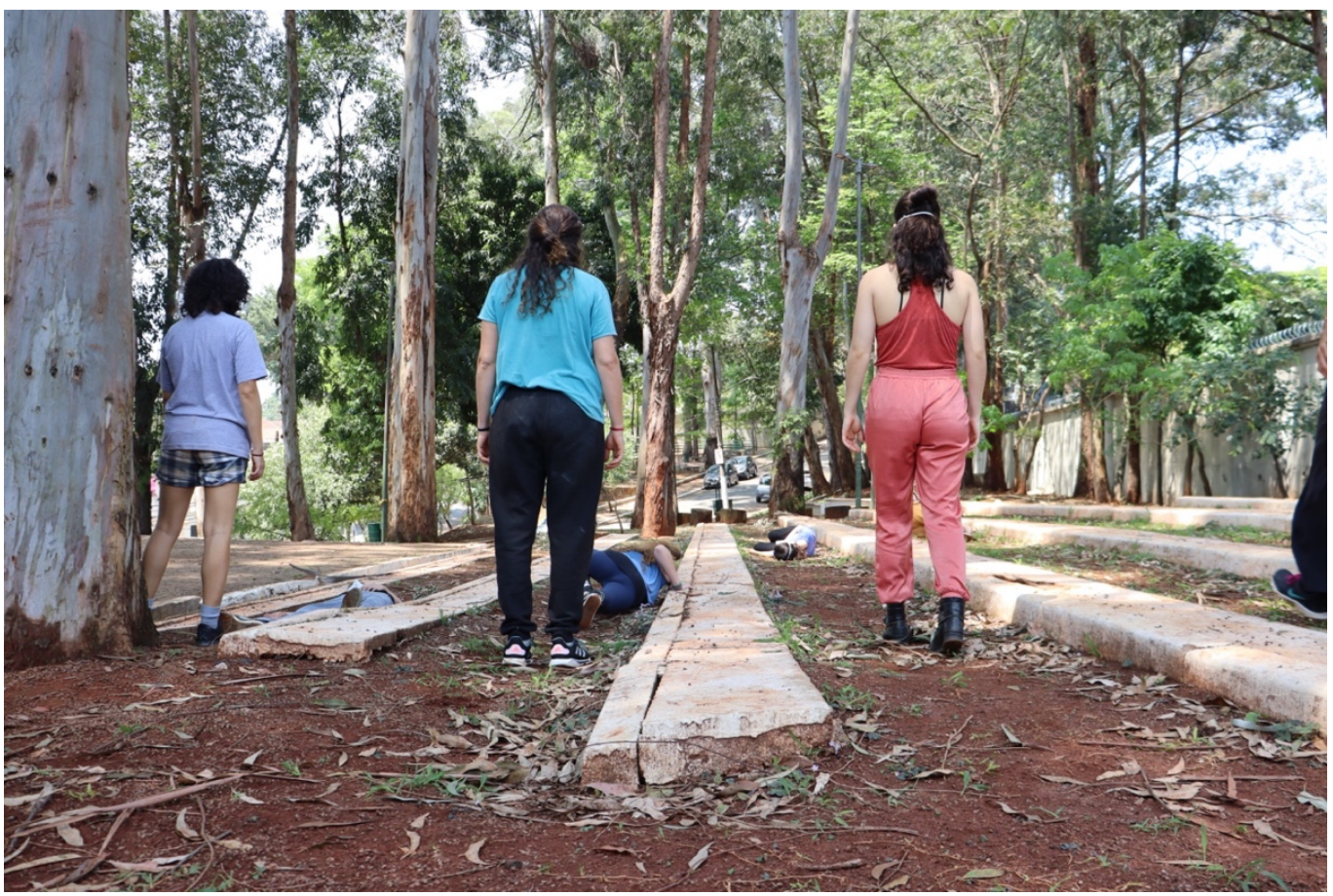


Figura 11 - Sessão aberta de improviso - Viewpoints na Praça Belisario Távora em São Paulo dia 26 de setembro de 2021. Marcella Vicentini, Morgana Siqueira, Alice Guêga, Carmen Estevez, Priscila Torres e Gustavo Curado - Foto: Catarina Guimarães Machado

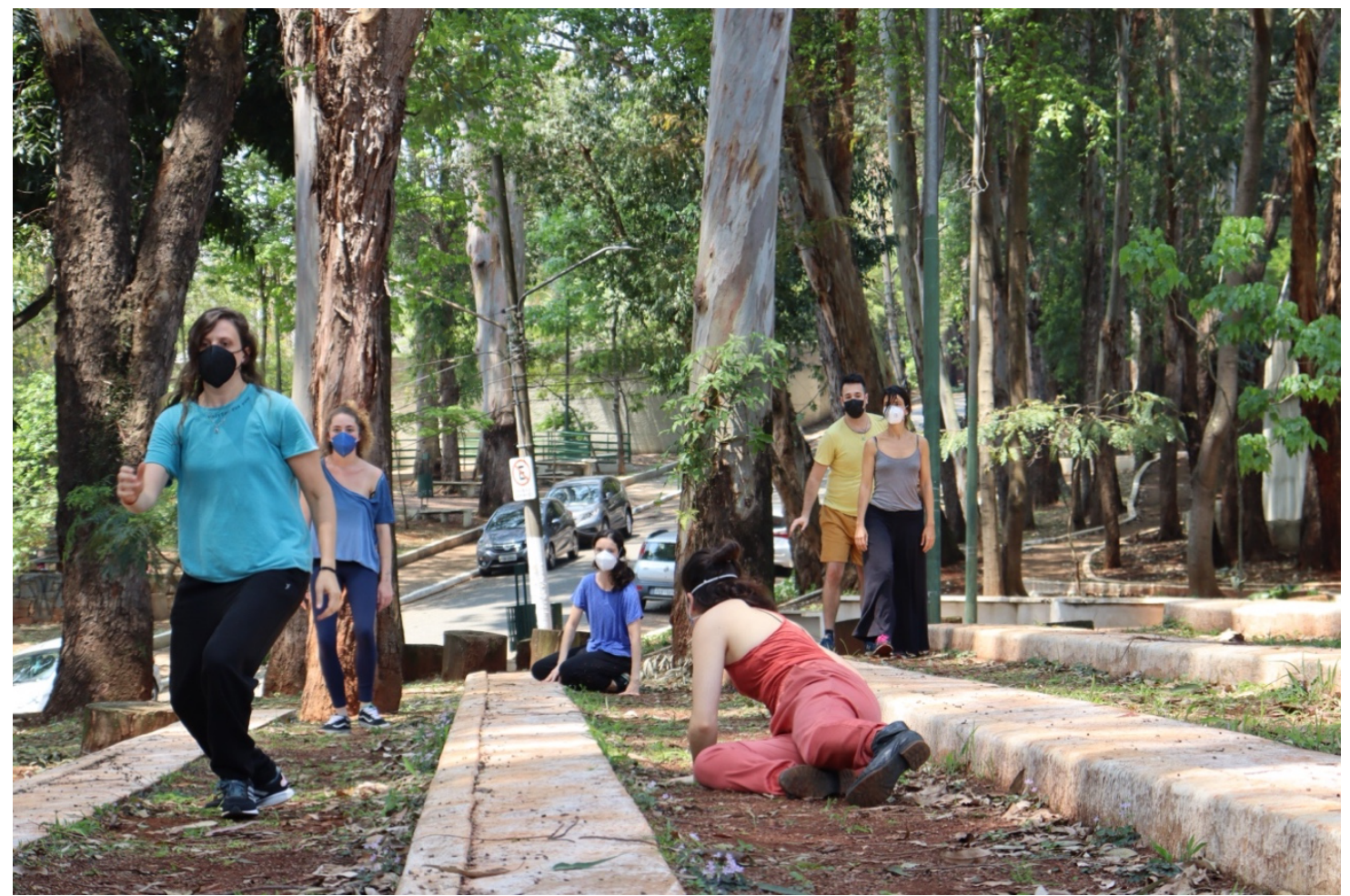

Agora eu dou um salto e me contradigo mais uma vez. Antes da pandemia, estava com vontades de experiências de treinos públicos, provocados por materialidades distintas, como luz, música, objetos, figurinos e matérias. Um ensaiar-se ao vivo, diante de... uma audiência.

Esse sonho de um projeto artístico tem a ver com o fato de que presenciei encantamentos em sessões de improviso inesquecíveis, e me pergunto se não fui egoísta pelo fato de que as experiências não foram partilhadas. Mas esse sonho só pode se dar no momento pós-pandemia, quando estivermos juntos presencialmente, ensaiando-nos novamente.

Por enquanto, o que nos apontou como uma boa estratégia é treinarmos em praças, uma vez por mês, num momento em que quase todos já tomaram a primeira dose da vacina: presencialmente, com máscara, iniciamos em junho de 2021 os encontros Viewpoints na Praça e manteremos esses treinos até 5 de dezembro de 2021. A cada mês, investigamos uma nova praça. É uma alegria sem 
fim presenciar artistas que nunca treinaram juntos se encontrarem pela primeira vez e partilharem experiências.

No dia 22 de setembro de 2021, retomamos o treinamento presencial no Estúdio Oito Nova Dança em São Paulo com máscara. O que posso dizer, a partir da experiência dos treinos na praça e desse retorno ao presencial, é que tenho a sensação de que amadurecemos muito durante a travessia da pandemia da Covid19. Estou assombrada com a escuta extraordinária, à flor da pele, e temos treinado especificamente as categorias de tempo (andamento, repetição, duração e resposta cinestésica) porque os treinos on-line, com todos os "delays" de nossas conexões de internet, não favoreciam as investigações relacionais sobre o tempo durante as sessões abertas de improviso. Esse assombro - a percepção da qualidade de escuta - tem me feito esperançar até mesmo em relação ao nosso país, esperançar que é possível acreditarmos em transmutações e ações mais coletivas na vida e na arte.

\section{Referências}

BOGART, Anne; LANDAU, Tina. O livro dos Viewpoints: um guia prático para Viewpoints e composição. Org. e trad. Sandra Meyer e equipe. São Paulo: Perspectiva, 2017.

FABIÃO, Eleonora. Corpo cênico, estado cênico. Contrapontos, v.10, n.3, p.321-326, set.-dez. 2010.

GUIMARÃES ROSA, João. Grande Sertão: Veredas. Rio de Janeiro: José Olympio Editora. 1965 [1956].

LARROSA, Jorge. A Operação Ensaio: sobre o ensaiar e o ensaiar-se no pensamento, na escrita e na vida. Educação \& Realidade, v.29, n.1, p.27-43, 2004.

LIMA, Tatiana Motta. Em busca (e à espreita) de uma pedagogia para o ator. Caderno de Registro Macu (Pesquisa), n.10, p.32-41, 1 semestre 2017.

LISPECTOR, Clarice. A paixão segundo G.H. Rio de Janeiro: José Olympio, 1977 [1964].

LODI, Fabiano. Direção teatral na perspectiva de Anne Bogart. 2015. Dissertação (Mestrado) - Universidade Estadual Paulista Julio de Mesquita Filho, Instituto de Artes, 2015. Disponível em: http://hdl.handle.net/11449/136698. 
OVERLIE, Mary. Standing in Space. The Six Viewpoints Theory \& Practice. Montana, EUA, 2016.

PERETTA, Eden Silva. Presença e inacabamento: aproximações entre a dança e o pensamento crítico de Paulo Freire. Urdimento - Revista de Estudos em Artes Cênicas, Florianópolis, v.3, n.36, p.376-395, nov./dez 2019.

RINALDI, Miriam Goldbaum. Teoria e prática do Viewpoints. 2016. Tese (Doutorado) - Escola de Comunicações e Artes, Universidade de São Paulo, São Paulo, 2016.

SANTOS, Juliana Reis Monteiro dos. Sob a perspectiva do instante: o teatro como lugar de construção de espaço-tempo singular. 2017. Tese (Doutorado) - Instituto de Artes, Campinas, Universidade Estadual de Campinas, São Paulo, 2017.

ZALTRON, Michele Almeida. Stanislávski e o trabalho do ator sobre si mesmo. São Paulo: Perspectiva: Centro Latino-Americano de Pesquisa Stanislávski (Claps), 2021.

Recebido em: 15/08/2021

Aprovado em: 23/11/2021 